\title{
USOS PRODUCTIVOS Y RITUALES DE LAS RUTAS INCAICAS DEL SECTOR CENTRAL DE LA QUEBRADA DE HUMAHUACA (JUJUY, ARGENTINA) ${ }^{1}$
}

\author{
PRODUCTIVE AND RITUAL USES OF THE INCA ROAD IN THE CENTRAL \\ SECTOR OF QUEBRADA DE HUMAHUACA (JUJUY, ARGENTINA)
}

\author{
Pablo Adolfo Ochoa ${ }^{2}$ y Clarisa Otero ${ }^{2,3}$
}

\begin{abstract}
En este artículo se discuten las lógicas de movilidad que condicionaron el trazado del qhapaq ñan en el sector central de la Quebrada de Humahuaca. Para ello se presenta un análisis funcional, arquitectónico y de emplazamiento del sistema de caminos poniendo énfasis en las rutas transversales al Río Grande, que bordearon y atravesaron el camino troncal. A este análisis se suma la identificación de numerosos tambos que articularon las redes viales para conectar la quebrada con otros ambientes y facilitar el flujo de recursos y bienes. Los resultados sugieren que parte de la adecuación de las arterias transversales estuvo condicionada por la producción agrícola intensiva y de objetos suntuarios en el Pucará de Tilcara, considerado la capital de la wamani de Humahuaca. Además, estos ramales habrían tenido un rol preponderante en la promulgación de las bases religiosas a partir de su configuración en torno al culto a las wakas. Proponemos a la quebrada como un caso particular de provincialismo inca en el que una región próxima a la frontera estatal y distante del centro del Imperio tuvo un alto grado de intervención y control directo sobre las poblaciones locales.
\end{abstract}

Palabras claves: vialidad incaica, producción artesanal, tambos, Quebrada de Humahuaca, control estatal.

In this article, we discuss the rationales behind the mobility that determined the layout of the qhapaq ñan in the central area of Quebrada de Humahuaca. We present a functional, architectural and site analysis of the road system, with an emphasis on the routes crossing to Rio Grande, where the main road was located. In addition to this analysis is the identification of numerous tambos articulating the road networks to connect the quebrada with other environments and to facilitate the flow of resources and goods. The results suggest that the layout of the main roads crossing the Inca route was shaped by the intensive production of agricultural resources and sumptuous objects in the Pucara de Tilcara, considered the capital of the wamani of Humahuaca. Furthermore, these branches may have had a principal role in the enactment of religious principles based on their configuration around the worship of the wakas. We propose that the quebrada was a particular case of Inca provincialism, where a region near the state border and distant from the center of the Empire had a high degree of intervention and direct control over local populations.

Key words: Inca road, network, craft production, tambos, Quebrada de Humahuaca, State control.

En los últimos años, las investigaciones en torno al sistema vial incaico buscaron caracterizar diferentes rutas articuladas a sitios arqueológicos que cumplieron con variadas funciones, para avanzar en la configuración de los paisajes prehispánicos, el desarrollo de los procesos de conquista y las formas de organización de las numerosas regiones que conformaron el Tawantinsuyu (Berenguer y Salazar 2017; Chacaltana et al. 2017; González Godoy 2017; Moralejo 2017; Ochoa y Otero 2017; Vitry 2017; Williams y Villegas 2017). Independientemente del énfasis puesto en los aspectos económicos, políticos o religiosos que modelaron el diseño y funcionamiento del qhapaq ñan en cada una de estas regiones, uno de los principales motivos de su trazado fue el de conectar el Cusco con las zonas periféricas para, entre otros fines, circular excedentes y producciones, que a modo de tributo eran enviados desde las provincias hasta la capital (Hyslop 1984). Este trazado a gran escala hizo que el camino real también funcionara como un instrumento ideológico y de poder. La instalación de redes viales en los

\footnotetext{
${ }^{1}$ Una primera versión de este trabajo fue presentada en el Qhapaq Ñan II, Taller Internacional en torno al Sistema Vial Inkaico (2427 de octubre de 2017), efectuado en Salta, Argentina. Este manuscrito fue evaluado por pares externos y editado por el Comité Editorial de Chungara y los editores invitados Carlos González y Christian Vitry.

${ }^{2}$ Instituto Interdisciplinario Tilcara, Facultad de Filosofía y Letras, Universidad de Buenos Aires, Buenos Aires, Argentina. pabloadolfoochoa@yahoo.com.ar; clarisaotero@yahoo.com.ar

${ }^{3}$ Instituto de Ecorregiones Andinas, Consejo Nacional de Investigaciones Científicas y Técnicas, Universidad Nacional de Jujuy, Jujuy, Argentina.
} 
puntos más extremos y de frontera del Imperio llevó a la conexión de territorios distantes y a legitimar la presencia del Estado en espacios que podían considerarse marginales (González Godoy 2017; Uribe 1999). A más de 30 años de la emblemática obra de Hyslop (1984), que marca el inicio de los estudios sistemáticos de los caminos, aún resta por avanzar en las utilidades que se les dieron en las provincias incaicas más septentrionales del noroeste argentino (Albeck 2016).

La Quebrada de Humahuaca, región que conformó una de las cuatro principales wamani del $\mathrm{NOA}^{1}$ (González 1982; Williams 2004), representa un caso de estudio en el que se pueden identificar distintos indicadores para evaluar las funciones específicas que tuvo el qhapaq ñan dentro de la estructura política estatal. El avance en las investigaciones arqueológicas desarrolladas en los últimos años en el sector central de esta región llevó a que previamente se planteara la utilidad del camino para el despliegue de prácticas religiosas vinculadas con la adoración a las wakas, el control del tránsito en las rutas que daban acceso a otros ambientes y la circulación de productos agrícolas ${ }^{2}$ (Ochoa y Otero 2017, 2018). Para dar continuidad a estas investigaciones y discutir el rol del sistema de caminos en una provincia distante del centro del Imperio, en este artículo se presentan las características de las rutas transversales al Río Grande y de siete tambos asociados a ellas. La identificación en este sector de la casi totalidad de las vías que pudieron funcionar durante la dominación incaica permitió además sumar a la reflexión el uso de los caminos en el marco productivo de bienes a gran escala. En esta oportunidad se integran a la discusión evidencias vinculadas a la producción especializada de objetos suntuarios de alto valor simbólico en el Pucará de Tilcara. Este poblado, localizado estratégicamente en el centro de la quebrada, posiblemente fue la capital incaica de la provincia de Humahuaca (González 1982; Otero 2015; Otero et al. 2018; Williams 2004) y uno de los principales centros de producción metalúrgica y lapidaria de la región (Otero y Tarragó 2017).

Los resultados demuestran que la red vial en esta wamani cumplió con múltiples funciones que facilitaron una fuerte intervención estatal y el control directo de la producción artesanal. En este sentido nuestro estudio sirve como un ejemplo a nivel macroregional para caracterizar la capacidad del Estado para integrar áreas distantes, e incluso próximas a las de frontera, mediante el anclaje de mecanismos económicos y religiosos. Asimismo, reconocemos que estos mecanismos se materializaron en la articulación de la red vial con centros productivos, tambos, espacios agrícolas, santuarios de altura, sitios estratégicos de control y fuentes de materias primas. Más allá de esta articulación, otro aspecto que sirvió para definir el paisaje vial de la región fue la detección de una amplia variedad de técnicas arquitectónicas utilizadas para construir los caminos. Para el período incaico se reconocen segmentos de distinta jerarquía según sus características funcionales y de emplazamiento. En trabajos previos hemos mencionado que los segmentos próximos a los sitios ceremoniales presentan rasgos distintivos para el área, posiblemente ligados a las prácticas rituales en tránsito y a la materialización simbólica de escenarios religiosos en el paisaje (Ochoa 2019). El resto de los trayectos que conforman la red vial exhiben diferentes características constructivas que en su mayoría responden a la topografía del terreno, entre ellas el despedrado, el uso de muros de retención lateral, el cavado sobre la roca madre y el amojonado simple y doble (Ochoa 2016).

\section{Área de Estudio}

La Quebrada de Humahuaca es un valle semiárido de más de $100 \mathrm{~km}$ de extensión. El Río Grande de Jujuy, la atraviesa en sentido norte-sur, siendo éste el principal curso de agua permanente (Figura 1). La quebrada se constituye como un corredor natural único, que comunica directamente la Puna con las Yungas y, en un plano más amplio, el área Circumpuneña con los Andes Meridionales (Tarragó 2013). A lo largo de su recorrido ofrece llanuras de inundación que en ocasiones superan los $3 \mathrm{~km}$ de ancho, mientras que en otros sectores puede angostarse hasta alcanzar solo $25 \mathrm{~m}$ de ancho. Estos angostos se encuentran asociados a quebradas tributarias del Río Grande, que han sido utilizadas como vías de interacción desde las primeras ocupaciones del territorio (Albeck 1992).

En este trabajo nos focalizamos en la construcción de la red vial incaica emplazada en el sector central de la quebrada. Este sector abarca el área que se extiende desde la Quebrada de Yacoraite, al norte, hasta la Quebrada de Purmamarca al sur. El límite este está definido por la Serranía de Tilcara, donde se registran extensos campos de cultivos prehispánicos interconectados (más de 900 ha), tambos, trayectos de caminos, incluidos dos de las principales rutas transversales que vinculan la quebrada con los Valles Orientales, y dos cerros que podrían considerarse las wakas tutelares de los tilcaras (Ochoa 2016, 2017b). En las crónicas, los tilcaras figuran como uno de los principales grupos étnicos que ocuparon el sector central de la quebrada (Sánchez 2004). El Cerro 


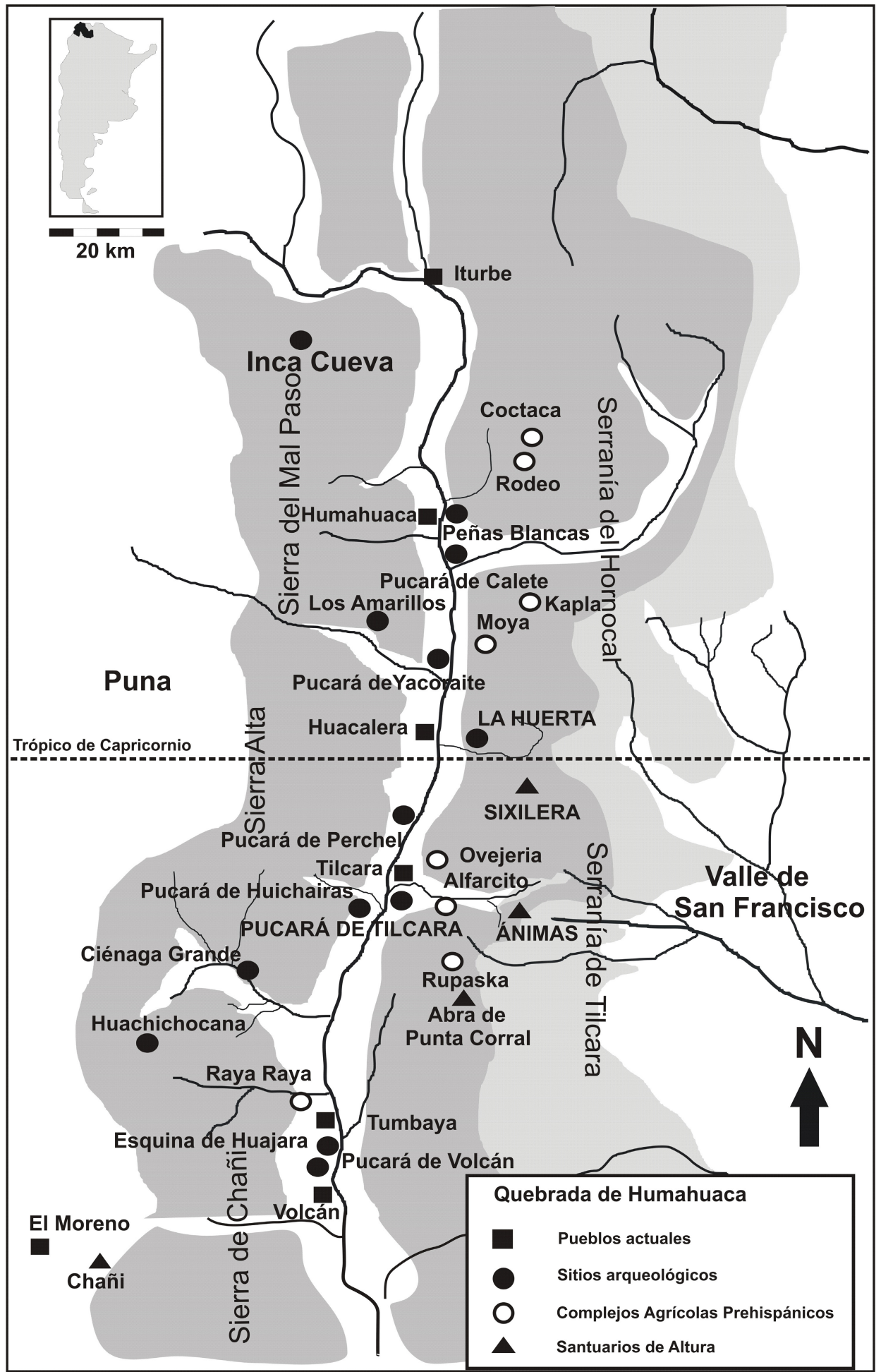

Figura 1. Mapa de la Quebrada de Humahuaca con la ubicación de los principales sitios arqueológicos que se mencionan en el texto.

Map of Quebrada de Humahuaca with the location of the main archaeological sites mentioned in the text. 
Sixilera y el Abra de Punta Corral continúan siendo referentes de memoria e identidad de los actuales pobladores del Departamento de Tilcara (Ochoa y Otero 2018). Ambos lugares son visitados por peregrinos de diferentes localidades de la provincia de Jujuy, que llegan a adorar a la virgen María en el marco de festividades católicas desarrolladas en fechas asociadas a los equinoccios.

La Sierra Alta define el límite oeste de la quebrada y la separa de la Puna. En los sectores superiores de esta sierra se identificaron varios trayectos de caminos prehispánicos y un tambo, instalado sobre una ruta transversal que conecta la Puna con el Pucará de Tilcara, emplazado en el sector central de esta sierra. Para reconocer la extensión y la diagramación del sistema de caminos de este sector, se incluyeron diferentes tramos identificados en las sierras del Aguilar y de Chañi. Se trata de segmentos de caminos prehispánicos que proceden desde el norte y sur de la Puna de Jujuy (Figura 2).

La metodología propuesta para cubrir la red de caminos contempló el relevamiento total del área mediante la prospección sistemática de los faldeos y cumbres de las sierras mencionadas, y de las quebradas transversales al Río Grande de Jujuy. Además, sobre estos cordones montañosos, que corren de forma paralela a la quebrada troncal, se marcaron extensas transectas perpendiculares a los ejes de tránsito, lo que permitió interceptar en diferentes sectores los distintos trayectos de las rutas transversales. Para esto se utilizó el sistema de georeferenciación satelital, que facilitó la búsqueda en el terreno de los distintos tramos de caminos y la localización de algunas estructuras asociadas a estas rutas.

Durante las tareas de prospección se realizó el registro planimétrico y arquitectónico de los segmentos de camino en mejor estado de conservación. Siguiendo diferentes criterios se pudo estimar el período cronológico en el que fueron construidos o remodelados. Debido a la amplia extensión del área de estudio, en este trabajo solo se presentan los tramos con rasgos constructivos incas, tales como empedrado, enlajado, adoquinado, amojonado, escalonado, entre muros de piedra, con muros de retención lateral y cavado sobre la roca madre. Para lograr un análisis integral se tuvo en cuenta la articulación de estos caminos con diferentes sitios con ocupaciones asignables al período incaico. Vale mencionar que durante los trabajos de relevamiento de las rutas se registraron nuevos sitios. Por sus características arquitectónicas y formas de emplazamiento, sumadas a la identificación del tipo de material cerámico

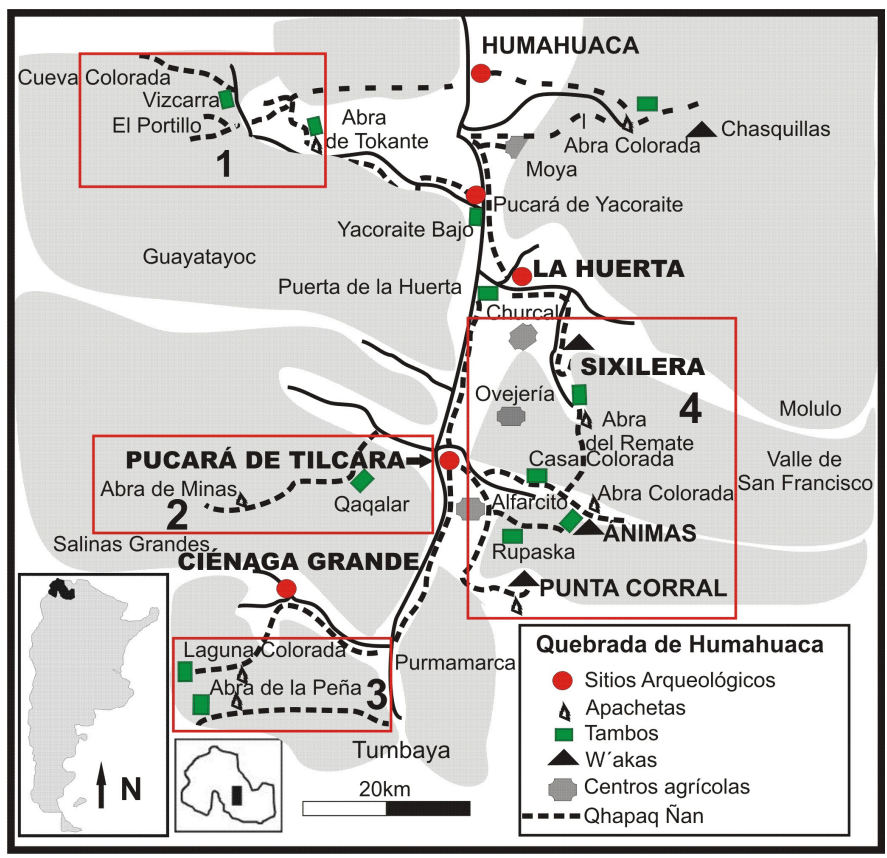

Figura 2. Mapa de la Quebrada de Humahuaca con la ubicación de los cinco ejes transversales para la interacción interregional, el sistema de tambos, principales centros administrativos, campos de cultivo y santuarios de altura. En rojo se indican las áreas relevadas.

Map of Quebrada de Humahuaca with the location of the five transversal axes for interregional interaction, the tambos system, strategic control sites, main administrative centers, cultivation fields and high-altitude sanctuaries. The four revealed areas are indicated in red. 
disperso en superficie, algunos de ellos pudieron ser definidos como tambos, mientras que otros fueron caracterizados como pequeños sitios ceremoniales asociados a la ritualidad del tránsito ${ }^{3}$. Las variables relacionadas con el tipo de emplazamiento ${ }^{4}$, los atributos arquitectónicos ${ }^{5}$, la extensión, su ubicación, el momento de ocupación de los sitios y caminos, y las características de los materiales registrados en superficie, se relevaron en fichas de registro (Tabla 1). A su vez, tal como se mencionó, para avanzar en la función de las rutas transversales en el marco de la circulación de bienes a escala interregional, se integraron los resultados del estudio del sistema vial con la información que se cuenta sobre la producción especializada de artesanías en el Pucará de Tilcara.

\section{La Conexión Vial de la Quebrada de Humahuaca con la Puna y los Valles Orientales}

En la década de 1980 se planteó que una de las principales arterias laterales del qhapaq ñan en Jujuy estuvo trazada en la Quebrada de Humahuaca, siguiendo el curso del Río Grande (Raffino 1981). A partir de nuestras investigaciones, desarrolladas en los últimos años, hemos detectado importantes vías que debieron conectar este camino troncal con rutas transversales para vincular a la quebrada con otros ambientes (Ochoa y Otero 2017). Hasta el momento se prospectaron más de 250 $\mathrm{km}$ de caminos de herradura, de los cuales $58 \mathrm{~km}$ corresponden a trayectos arqueológicos que por sus características arquitectónicas se puede estimar que formaron parte de la red vial incaica. Además, el relevamiento de estos trayectos permitió identificar nuevos tambos emplazados en las serranías que enmarcan la quebrada, sumando siete a los previamente detectados (Ochoa y Otero 2017). También se encontraron 10 apachetas y materiales arqueológicos en sus alrededores que pudieron ser parte de las ofrendas depositadas como "pagos" durante el paso entre ambientes (Pimentel 2009). Entre los tramos de caminos más representativos del sector central de la quebrada, reconocemos una diversidad de técnicas constructivas que reflejan no

Tabla 1. Características arquitectónicas y distancia de los tramos de camino y de los tambos presentados en el trabajo.

Architectural characteristics and distance of the road sections and the tambo presented in the article.

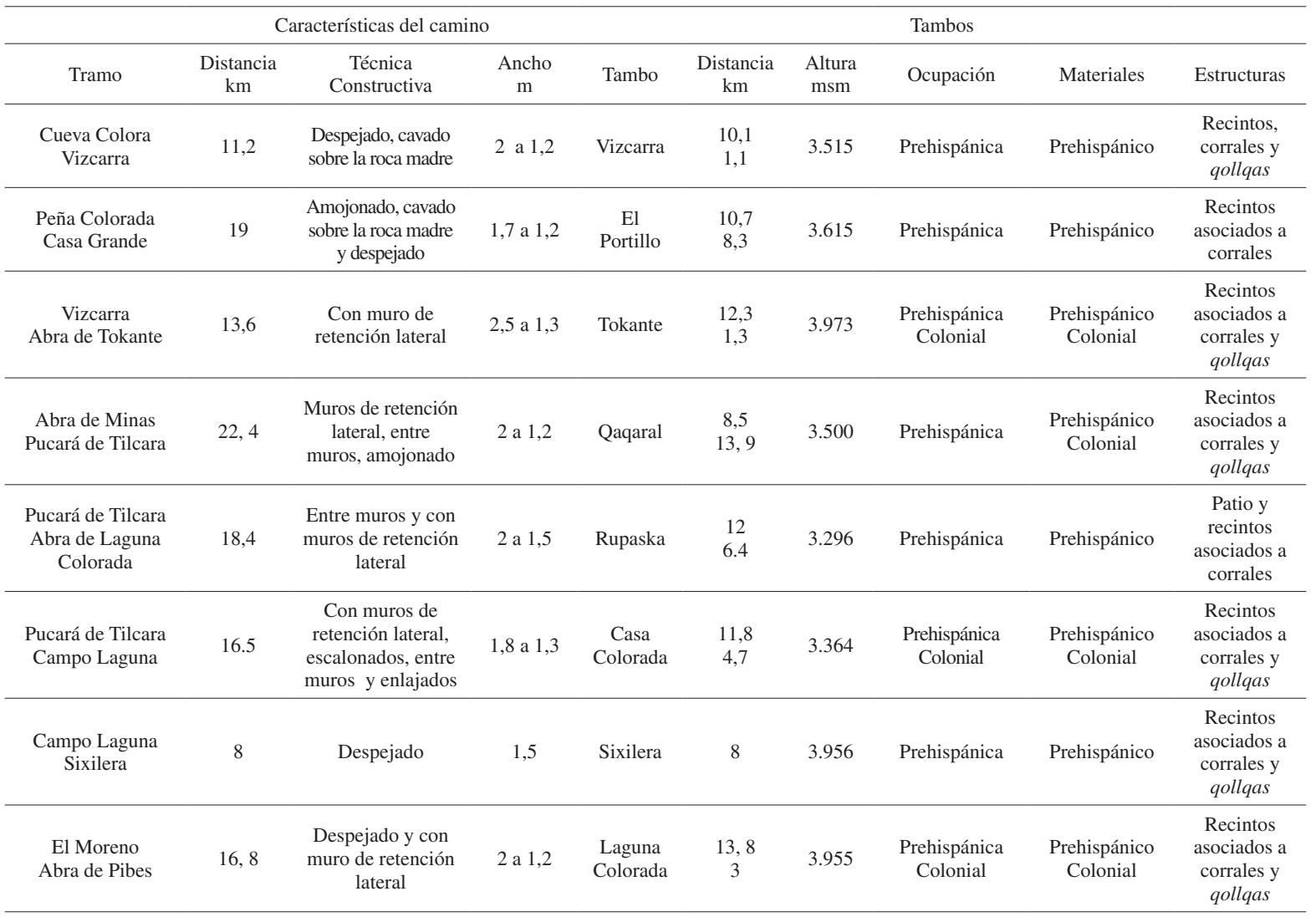


solo la necesidad de ajustarse a las características topográficas de la región, sino que además demuestran que debieron construirse buscando facilitar el flujo de materias primas y bienes, y el acceso a los santuarios de altura (Figura 2).

\section{La Sierra del Aguilar}

Se trata de un gran macizo que se interpone entre el sector norte de la Quebrada de Humahuaca y la Cuenca de Miraflores en la Puna de Jujuy. En esta sierra se identificaron tres arterias de caminos que provienen desde la Puna. La detectada más al norte, posiblemente nacía en la localidad de Casabindo, la identificada en el sector central procede desde la actual Mina del Aguilar; y la tercera, al sur, proviene desde Susques, pasando por Rinconadillas (Figura 2). Los tres trayectos atraviesan la Sierra del Aguilar para ingresar a la Sierra del Mal Paso, donde se bifurcan hacia Humahuaca o Yacoraite, en el sector norte y central de la Quebrada de Humahuaca, respectivamente (Figura 2). El tramo que ingresa desde el norte, de 11,2 km de extensión, fue prospectado desde Cueva Colorada hasta Vizcarra. Presenta diferentes técnicas constructivas, tales como tramos despejados, con muros de retención lateral, cavado sobre la roca madre y escalonado (Tabla 1). El camino prehispánico del sector central, que atraviesa el Abra Colorada, fue localizado en las cercanías de la Cueva del Portillo (Fernández
1998), donde se une con la arteria transversal que procede desde el sur. Este segmento de camino, de $2 \mathrm{~km}$ de extensión, se construyó entre muros de piedra y cavado sobre la roca madre (Figura 3a). Sobre la falda de la Sierra del Mal Paso, otro segmento de $6 \mathrm{~km}$ une ambas arterias (Figura $3 \mathrm{~b}$ y c). Esta encrucijada de caminos permite acceder por el norte al Pucará de Peñas Blancas en la localidad de Humahuaca y por el sur, a través del Abra de Tokante, a la Quebrada de Yacoraite.

En la Quebrada de Tokante identificamos un segmento de camino de $4 \mathrm{~km}$ que conduce al abra homónima. En la mitad de su recorrido se encontró un conjunto de estructuras, emplazadas a $4.000 \mathrm{msm}$ sobre un afloramiento rocoso, protegidas por grandes lajas de hasta $5 \mathrm{~m}$ de altura (Figura 4a). La traza del camino pasa por el interior de este conjunto de estructuras, al que denominamos Tambo de Tokante (Figura 4b). Entre los materiales registrados en superficie abundan las lascas de obsidiana y de sílice gris, trozos de mineral de cobre y fragmentos de cerámica arqueológica. El camino continúa hasta el Abra de Tokante, donde también se registraron una gran cantidad de materiales prehispánicos asociados a una apacheta (Ochoa y Otero 2017) (Figuras 4c, 4d, 4e y 4f).

\section{La Sierra Alta}

La Sierra Alta, tal como se mencionó, es un cordón montañoso que separa al sector sur de la
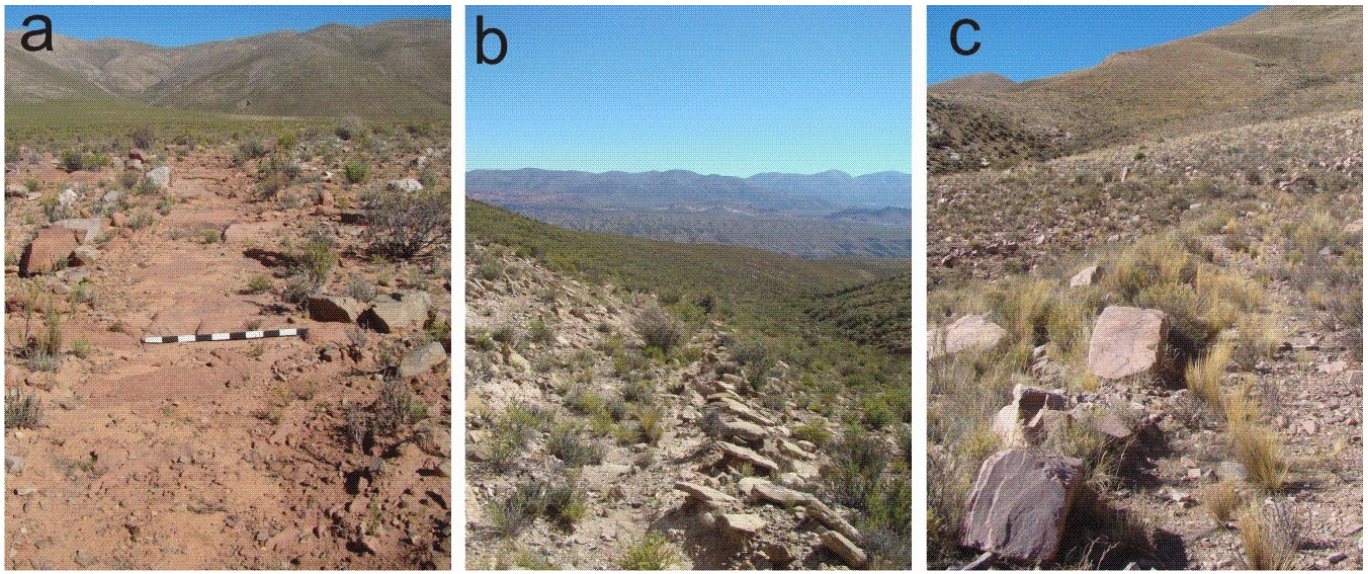

Figura 3. Tramos de camino inca localizados en la Sierra del Aguilar. (a) Trayecto Abra Colorada-Casabindo, cavado sobre la roca madre y amojonado lateral. (b) Trayecto Vizcarra-Tokante, con muros de retención lateral. (c) Trayecto El Portillo-Abra del Mal Paso, con muros de retención lateral y amojonado.

Inca road sections located in the Sierra del Aguilar. (a) Abra Colorada-Casabindo route, dug on the cairn and lateral decking. (b) Vizcarra-Tokante route, with lateral retaining walls. (c) Portillo-Abra del Mal Paso route, with lateral retaining walls. 

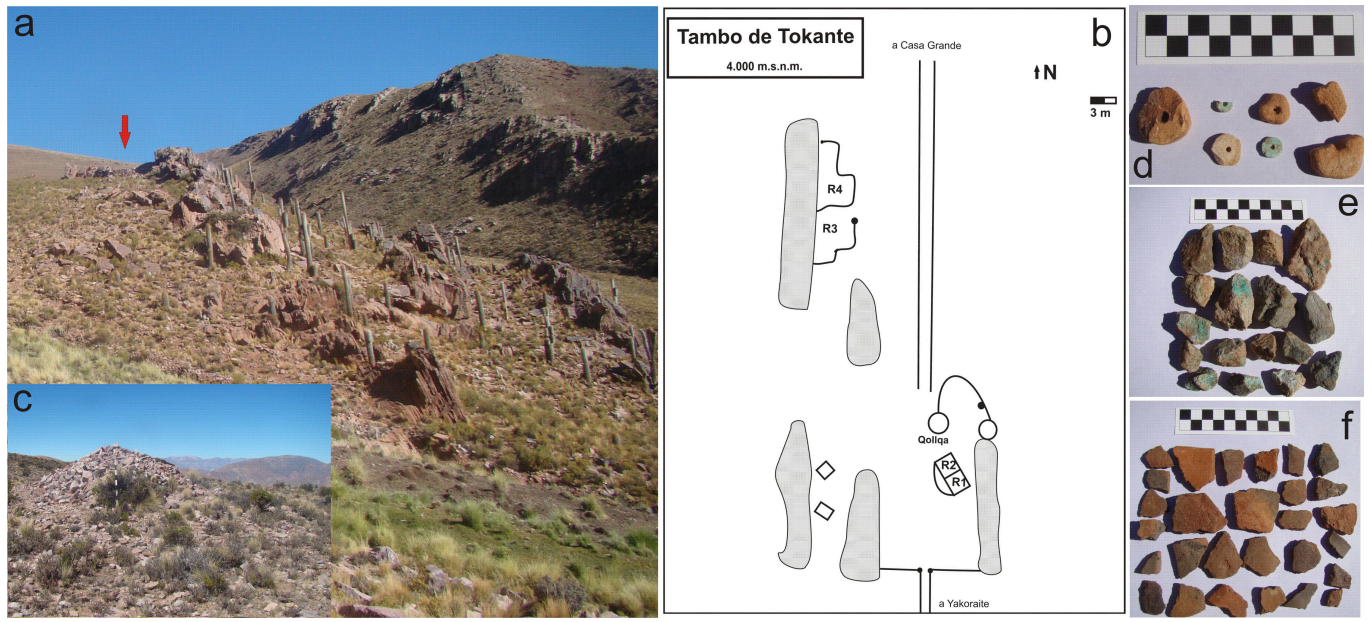

Figura 4. Tambo de Tokante. (a) Vista panorámica. (b) Planimetría. (c) Apacheta del Abra de Tokante. Materiales registrados en los alrededores de la apacheta: (d) Cuentas de collar. (e) Trozos de mineral de cobre nativo. (f) Fragmentos de cerámica.

Tokante Tambo. (a) Panoramic view. (b) Planimetry. (c) Apacheta del Abra de Tokante. Materials collected in the surroundings of the apacheta: (d) Collar beads. (e) Pieces of native copper ore. (f) Ceramic fragments.

Puna de Jujuy del sector central de la Quebrada de Humahuaca. En esta sierra se registró un importante camino prehispánico que continúa en uso. Procede de las Salinas Grandes y llega de forma directa al Pucará de Tilcara. Presenta técnicas constructivas de clara factura incaica como el escalonado y la colocación de mojones para delimitar su ancho, que en algunos tramos supera los dos metros (Figura 5a). A lo largo de su recorrido se detectó un tramo de 300 m de extensión, asociado a un sitio prehispánico, al que denominamos Tambo de Qaqalar. Este tambo, construido a 3.500 msm y a $14 \mathrm{~km}$ del Pucará de Tilcara, está compuesto por tres recintos, dos qollqas y un corral (Figura 5b). Durante su relevamiento no se encontraron evidencias que permitan estimar que estuvo ocupado durante el período Colonial. Al igual que en otros casos, el camino inca atraviesa el sitio y su ingreso está señalizado por dos jambas. A unos metros de estas últimas y colocadas sobre este trayecto de camino se identificaron dos grandes piedras que pudieron demarcar el ingreso a un nuevo territorio étnico y a su vez, reforzar la geografía sagrada del paisaje ritual (Figura 5c) (Ochoa 2019). Por la disposición de estas piedras y la gran cantidad de fragmentos de cerámica atribuibles al Estilo Humahuaca N/R (negro sobre rojo), característico del período de Desarrollo Regionales Tardío e Inca, que se encontraron a su alrededor, quizás se trate de tokankas -piedras sagradas que jerarquizaban los caminos, protectoras tanto de las personas como de los animales, materias primas y productos en tránsito (Hyslop 1984)-. En las proximidades de este tambo se detectó otro segmento de camino de un kilómetro de extensión que también presentaba marcados rasgos constructivos incaicos. En algunos sectores cuenta con escalones de importantes dimensiones y se encuentra amojonado con grandes piedras y muros de retención lateral. En su último trayecto, esta arteria transversal que ingresa desde la Puna por el Abra de Minas, desciende por la Quebrada de Huichairas hasta desembocar en el Pucará de Tilcara.

\section{La Sierra de Chañi}

La Sierra de Chañi separa el sector sur de la Quebrada de Humahuaca de las Salinas Grandes de Jujuy. En esta sierra identificamos dos segmentos de camino de herradura que se emplazan de forma paralela, separados entre sí por $2 \mathrm{~km}$ de distancia. A través de la Quebrada de Huachichocana conectan la localidad actual de El Moreno, donde existió un importante tambo incaico, con el sitio arqueológico Ciénaga Grande. Este poblado se emplaza en el sector central de la Quebrada de Purmamarca, la cual es tributaria de la Quebrada de Humahuaca. Posiblemente también funcionó como un tambo de gran envergadura durante la dominación incaica, dada su localización en el paisaje y el número de piezas cerámicas de filiación cuzqueña recuperadas durante las excavaciones realizadas por A. Salas (1945).

En los alrededores del Abra de Pives, por donde ingresa uno de estos caminos de herradura, se registraron materiales arqueológicos en superficie asociados a la apacheta prehispánica. Asimismo, se identificaron a casi $4.000 \mathrm{msm}$ segmentos de qhapaq ñan de un metro de ancho que presentan importantes muros de retención lateral. 

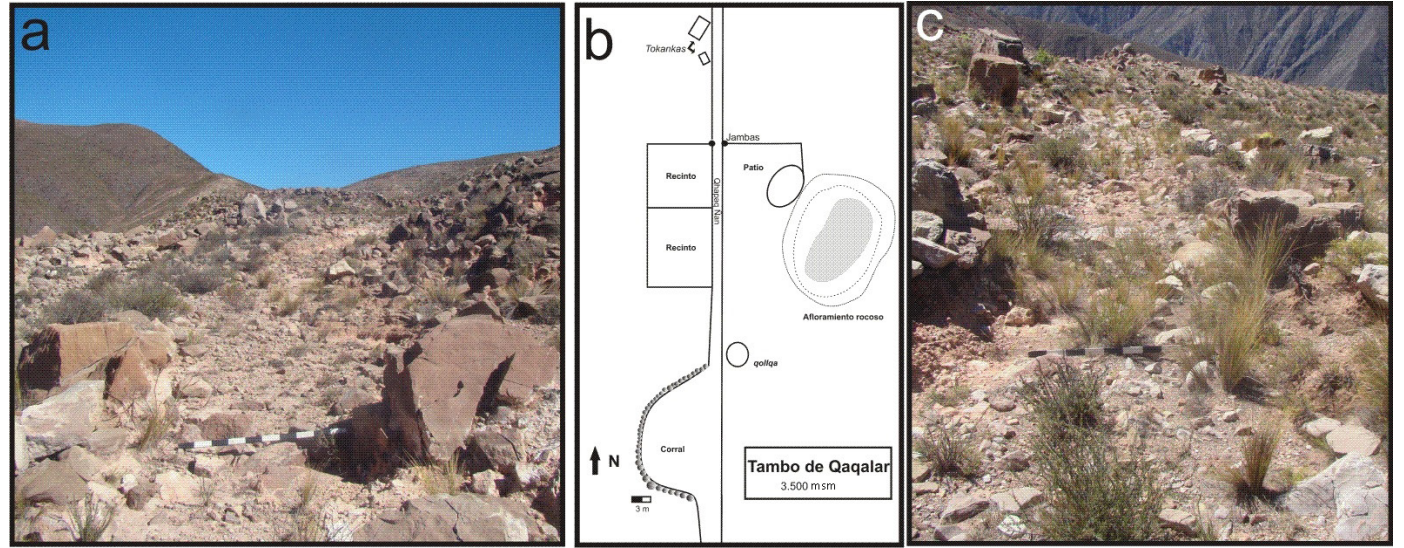

Figura 5. Tambo de Qaqalar. (a) Camino de ingreso al tambo, amojonado con grandes piedras. (b) Planimetría. (c) Grandes Tokankas ubicadas a la vera del camino inca a metros del ingreso al tambo.

Qaqalar Tambo. (a) Entrance road to the tambo, cairned with large stones. (b) Planimetry. (c) Large Tokankas located on the side of the Inca road a few meters from the entrance to the tambo.

Sobre la falda de la Sierra de Chañi, entre los segmentos de caminos de herradura antes mencionados, se localizó un tambo construido sobre una peña blanca a $3.900 \mathrm{msm}$. Este tambo, al que denominamos Tambo de Laguna Colorada por su emplazamiento, resalta en el paisaje. Se estructura a partir de cuatro recintos, dos qollqas y un gran corral (Figuras 6a y 6b). En superficie se registraron abundantes fragmentos de cerámica prehispánica, numerosos morteros planos y dos manos de moler.

Por otro lado, asociado a la ruta transversal que vincula el Tambo de El Moreno con Tumbaya Grande, en el sector sur de la Quebrada de Humahuaca, detectamos un nuevo tambo al que llamamos Tambo del Abra de la Peña (Figura 6c). Está construido sobre un elevado afloramiento rocoso que se encuentra frente a la desembocadura de la quebrada homónima, próximo a un cruce de caminos prehispánicos a 3.929 msm y a $6 \mathrm{~km}$ de distancia de la localidad de El Moreno. Presenta un corral y cuatro recintos, uno de los cuales posee una pared canteada de forma regular con una hornacina (Figura 6d). Desde este tambo se puede observar el Cerro Chañi, antigua waka prehispánica y escenario de Capac Cocha (González Turu y Vitry 2006), distante a solo 7 km.
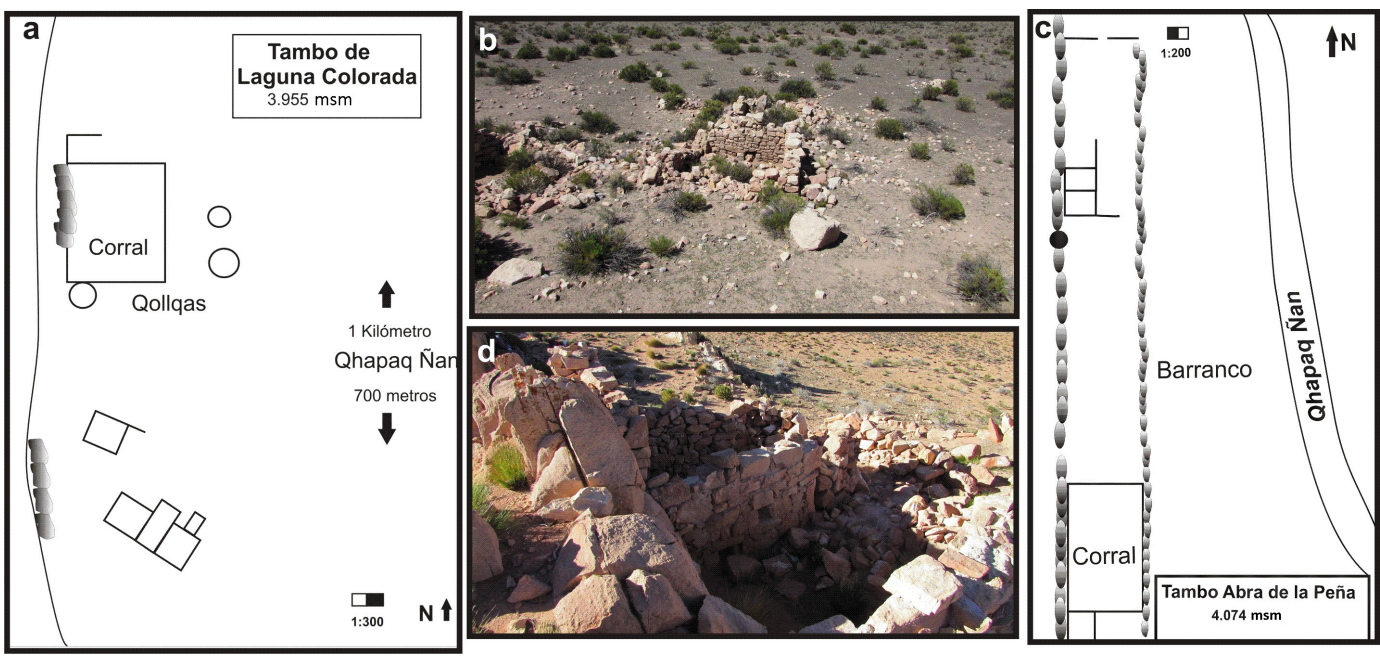

Figura 6. (a) Planimetría del Tambo de Laguna Colorada. (b) Vista panorámica del tambo. (c) Planimetría del Tambo Abra de la Peña. (d) Detalle de la arquitectura donde se destaca el canteo regular de los muros y una hornacina.

(a) Planimetry Laguna Colorada Tambo. (b) Panoramic view of the tambo. (c) Planimetry of the Abra de la Peña Tambo. (d) Detail of the architecture where the regular cutting of the stone walls and a niche stand out. 


\section{La Serranía de Tilcara}

Sobre la Serranía de Tilcara y vinculando el Pucará homónimo con los Valles Orientales de Jujuy registramos cuatro segmentos de caminos de herradura que en distintos tramos presentan escalones, muros de retención lateral, trayectos en zigzag y mojones laterales. Dos de estos cuatro segmentos fueron descriptos en trabajos previos en los que se enfatizó su reutilización en el marco de peregrinaciones católicas actuales, ya que estos caminos vinculan la localidad de Tilcara con las capillas que se encuentran emplazadas sobre las faldas de la serranía homónima (Otero y Ochoa 2011; Ochoa 2016, Ochoa y Otero 2017, 2018).

El camino que conduce desde Tilcara al paraje de Sixilera, donde detectamos un santuario de altura prehispánico (Ochoa 2017b), atraviesa el faldeo del Cerro Negro, los campos de cultivo prehispánicos de Ovejería y la falda superior de la Serranía de Tilcara. Este camino desemboca en la Capilla de Nuestra Señora del Rosario de Sixilera, pero a su vez se conecta con los segmentos de camino que llevan al santuario prehispánico emplazado en la cima del Cerro Sixilera, caracterizado como una de las principales wakas de la región (Ochoa 2016, 2017a y b; Ochoa y Otero 2017, 2018). Estos tramos se destacan por presentar una gran variedad de técnicas constructivas incaicas, entre las que mencionamos: segmentos escalonados, enlajados, con muros de retención lateral, entre muros de piedras, y amojonados simples y dobles (Ochoa 2017a).

El segundo camino que desde Tilcara conduce en dirección suroeste al otro centro de peregrinación católica, también atraviesa campos de cultivo prehispánicos, en este caso los de El Alfarcito. Si bien este camino desemboca en la actual Capilla de la Virgen de Copacabana del Abra de Punta Corral, en el trayecto que continua hacia el abra homónima donde se emplaza el santuario de altura prehispánico se identificó un tramo de qhapaq ñan de $600 \mathrm{~m}$ de largo que presenta segmentos empedrados, enlajados y amojonados en ambos extremos (Ochoa y Otero 2018).

Los dos segmentos restantes de camino, hacia el Abra Colorada al sureste y hacia Campo Laguna al este, se bifurcan a partir de una arteria transversal posiblemente reconstruida durante la época Colonial. Esta arteria presenta malas condiciones de conservación por la acción del escurrimiento de diferentes cárcavas. En el camino que se dirige hacia el Abra Colorada, antes de llegar a la falda de la Serranía de Tilcara, se detectó un segmento de camino inca de un $\mathrm{km}$ de extensión, construido entre muros de piedra (Figura 7a). Asociado a este tramo identificamos terrazas y andenes de cultivo, y un tambo, al que denominamos Tambo de Rupaska, emplazado sobre un pequeño morro a $3.296 \mathrm{msm}$, a $12 \mathrm{~km}$ de distancia del Pucará de Tilcara y a 6 $\mathrm{km}$ del Abra de Laguna Colorada. Este sitio se compone de tres estructuras con divisiones internas, que generan recintos cuadrangulares de pequeñas dimensiones sobreelevados y articulados a un gran espacio delimitado por un muro perimetral curvo, el cual posiblemente funcionó como corral (Figura 7b). En estas estructuras se registraron en superficie fragmentos de cerámica de Estilo Humahuaca N/R, tres puntas de proyectil de base escotada confeccionadas en obsidiana y en sílice gris, y tres cuentas discoidales elaboradas en piedra caliza (Figura 7c). Estos materiales fueron asignados cronológicamente a los períodos Medio, de Desarrollo Regionales Tardío e Inca.

El cuarto trayecto de camino se dirige hacia las localidades de El Durazno y El Molulo, pasando también por el paraje de Campo Laguna. Esta arteria, que presenta atributos tanto prehispánicos como coloniales, ha sido reutilizada a través del tiempo por tratarse del corredor natural de más rápido acceso a las yungas. A 11,8 km del Pucará de Tilcara, sobre la serranía homónima, se detectó un corral actual reconstruido sobre un conjunto de estructuras prehispánicas emplazadas a 3.364 msm (Figura 8a). Más allá del grado de alteración como causa de la reutilización del espacio, se reconoció que el sitio original se encontraba atravesado por un corto trayecto de camino incaico de $30 \mathrm{~m}$ de largo, confeccionado a partir de la técnica constructiva de escalonado entre muros de piedra (Figura 8b). Además, se pudo determinar que contaba con por lo menos tres recintos. A un km de este sitio, al que denominamos Tambo de Casa Colorada, en el camino que conduce a los valles, se detectó un tramo empedrado y enlajado del qhapaq ñan (Figura 8c).

En el paraje de Campo Laguna localizamos otro importante trayecto de camino inca de $3 \mathrm{~km}$ de extensión y $11 \mathrm{~m}$ de ancho. Este trayecto corresponde a una calzada ritual que fuera utilizada para ascender al santuario de altura de la serranía de las Ánimas (Ochoa 2019). En este paraje detectamos otra posta incaica, que denominamos Tambo de las Ánimas. Un kilómetro antes de este tambo, tomando un desvío hacia el norte por el Abra del Remate, el camino se redirecciona hacia el sector superior de la Quebrada de Sixilera. En la base del cerro Sixilera, a $3.956 \mathrm{msm}$, se registró el Tambo de Sixilera (Figura 9a). En el interior de sus estructuras, confeccionadas en cuarcita rosada, se hallaron tres puntas de proyectil de base escotada y varios fragmentos de cerámica de Estilo Humahuaca N/R (Figura 9b). A su vez, este tambo se encuentra asociado al trayecto de camino inca que conduce 


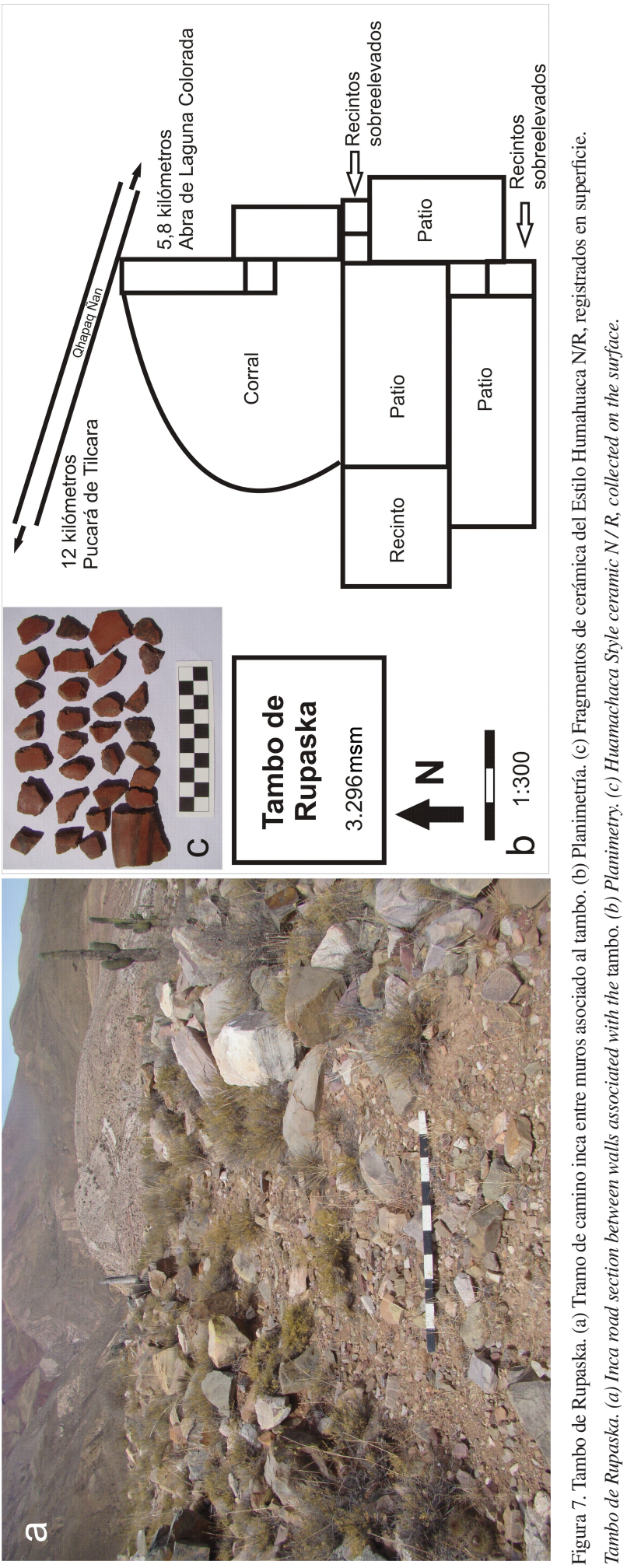




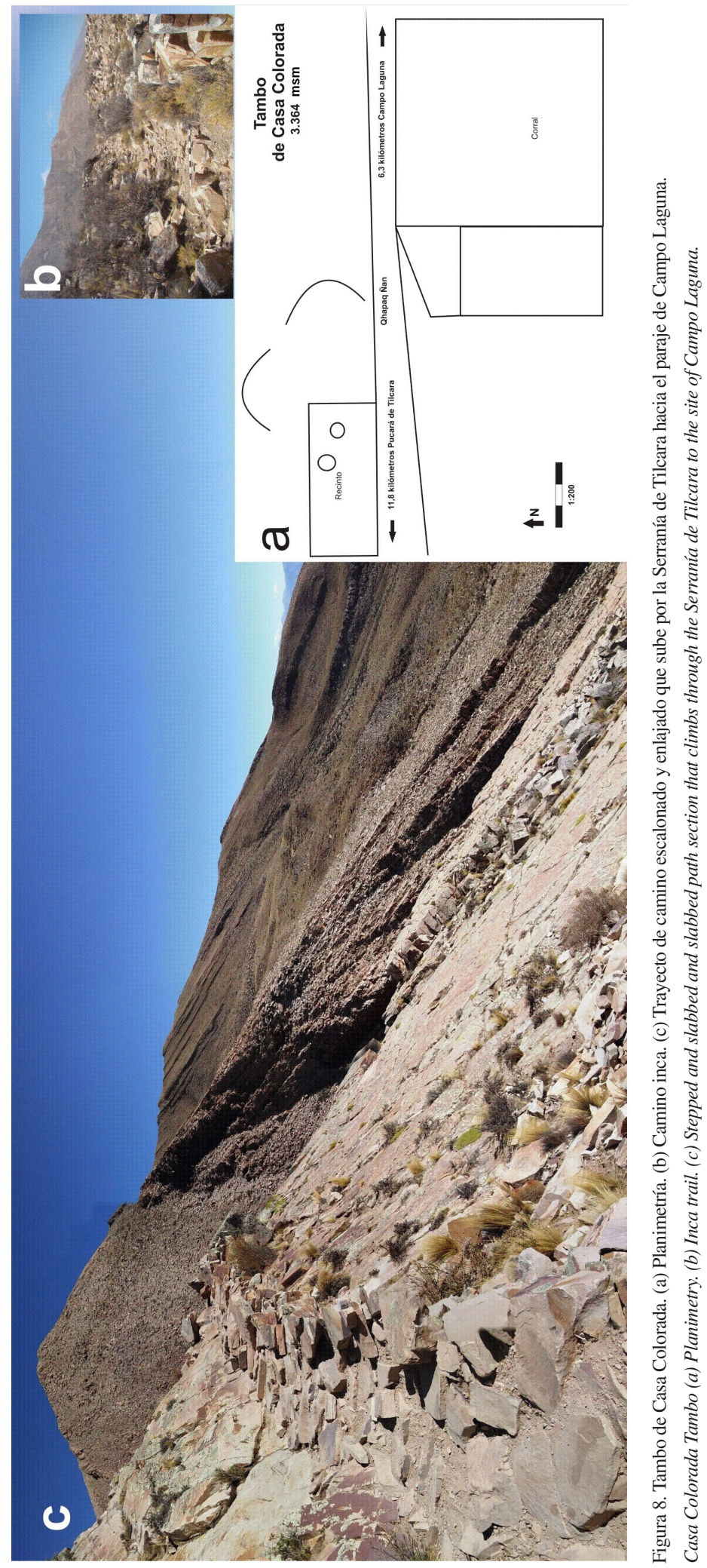


al santuario de altura del cerro Sixilera, que fuera descrito previamente por su emplazamiento en zigzag, escalonado y amojonado (Ochoa 2016, 2017b). Por último, es de destacar que en el Abra del Remate también se detectó una apacheta, emplazada a $4.435 \mathrm{msm}$ (Figura 9c). En superficie se registró una importante cantidad de fragmentos de cerámica de Estilo Humahuaca N/R (Figura 9d) $\mathrm{y}$ varios trozos de mineral de cobre nativo.

\section{El rol del Pucará de Tilcara en la producción especializada de bienes suntuarios}

El Pucará de Tilcara fue el poblado prehispánico de mayor extensión de la Quebrada de Humahuaca, llegando a alcanzar en momentos incaicos una superficie de 17,5 ha. Durante la dominación incaica, se reconfiguró su traza edilicia para adecuar el poblado preexistente a los requerimientos estatales. Al igual que otros grandes sitios incaicos de carácter multifuncional, sumado a su rol como capital de wamani y uno de los principales centros productivos de la región, debió constituirse como un poblado sumamente dinámico. Para responder a esta dinámica, es posible estimar que parte de la red vial emplazada en el sector central de la quebrada también se adecuara a las funciones productivas y político administrativas del pucará.

Hasta el momento, a lo largo de las 32 agrupaciones de viviendas, edificios ceremoniales y plazas que lo componen, para las cuales aún no se puede sostener si se trataron de barrios de artesanos o de casas habitadas por pobladores de acuerdo a su origen étnico, registramos 57 talleres ocupados por unidades productivas insertas en la estructura económica estatal. Estos talleres estuvieron destinados a la producción especializada de bienes suntuarios de alto valor simbólico, confeccionados en metal (oro, plata, bronce estañífero y cobre) y en distintas variedades de rocas (Otero 2015; Otero y Tarragó 2017).

Una de las principales actividades artesanales fue la manufactura de pendientes, ornamentos, torteros, vajilla ritual (cucharillas, cuencos) e illas (modelados zoomorfos y fitomorfos de uso ceremonial) de alabastro, caliza, ónix y travertino (Figura 10a, b, c, d y e). Parte de estos objetos, que en su mayoría muestran atributos estandarizados, presentan características similares con algunas piezas halladas por Bingham en Machu Picchu (Rowe 1946), y por Valcárcel $(1934,1935)$ en sepulturas de Sacsahuaman. Hasta el momento no existen referencias sobre la elaboración de este tipo de artesanías en otros sitios del Tawantinsuyu. Otro aspecto que resulta llamativo es que la mayoría de los objetos hallados en el pucará, principalmente los pendientes y torteros, se encuentren incompletos o en proceso de elaboración. Se trata de cientos de preformas, piezas fracturadas o con errores de manufactura. Es posible que las piezas correctamente elaboradas, incluidas los ornamentos, recipientes rituales e illas, una vez terminadas hayan sido distribuidas a otras regiones o utilizadas en contextos aún no excavados de la Quebrada de Humahuaca, como los santuarios de altura. Junto al aprovechamiento de este tipo de rocas más blandas, también se utilizaron sílices de diferentes tonalidades. Si bien en los talleres del pucará recuperamos centenares de lascas y decenas de bloques de pedernal gris a blanco traslúcido, no detectamos preformas, y menos aún formas completas. A partir de la dureza y la fractura de estos pedernales, y del tipo de lascas y microlascas halladas, es posible estimar que fueron utilizados para confeccionar puntas de proyectil u otro tipo de objetos de reducido tamaño.

\section{Discusión}

En la búsqueda de medios y fuerzas productivas que facilitaran la especialización artesanal en las provincias, la elaboración de bienes suntuarios en el Pucará de Tilcara pudo ser uno de los principales motivos que llevaron a la creación de un espacio integrado en el sector central de la Quebrada de Humahuaca. La red vial debió ser fundamental para garantizar la circulación de personas, materias primas y productos terminados. El aprovisionamiento de travertinos, sílices, ónix y minerales metalíferos de fuentes ubicadas en la Puna y su traslado hasta el pucará para ser distribuidos en numerosos talleres dedicados a la elaboración de un mismo tipo de artesanías, reflejan una rigurosa organización de la producción con el propósito de ser desarrollada a gran escala y de manera intensiva.

El sistema de caminos y tambos construidos en las sierras Alta, del Mal Paso, del Aguilar y de Chañi permitió conectar de forma directa el sector central de la Quebrada con la Puna. Su diseño y trazado demuestra una diagramación planificada del paisaje. Los tambos no solo se encuentran ubicados estratégicamente próximos a vertientes naturales de agua o vegas de altura, sino que también presentan una distancia regular de entre 10 y $15 \mathrm{~km}$, dependiendo de la dificultad del terreno (Tabla 1). Esta distancia representa una jornada de caminata desde los principales poblados prehispánicos de la quebrada o dos jornadas para atravesar las sierras. Si bien las características constructivas de estos tambos son heterogéneas, su función como postas para el descanso y aprovisionamiento debieron ser las mismas. Es 

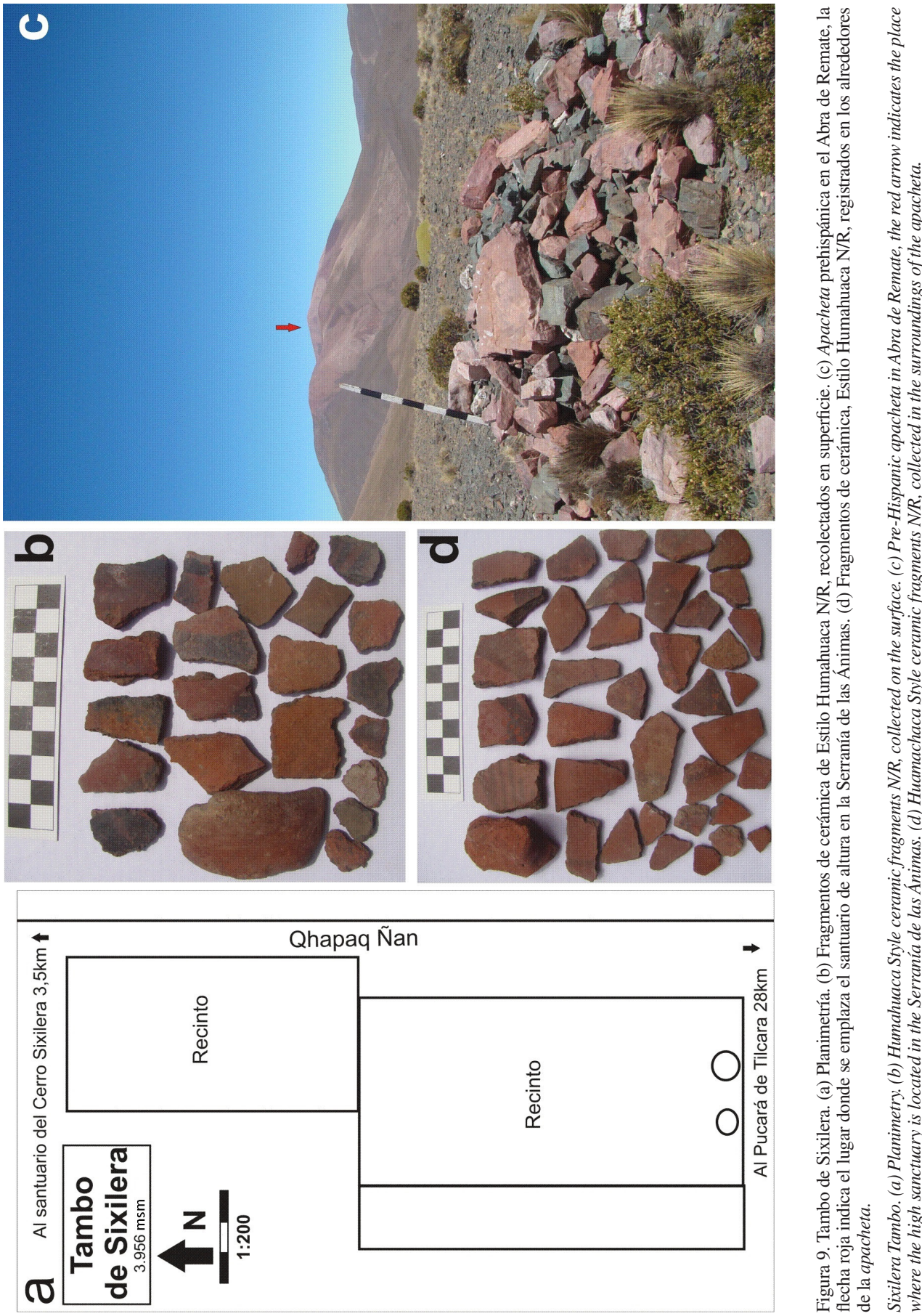

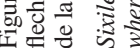


a

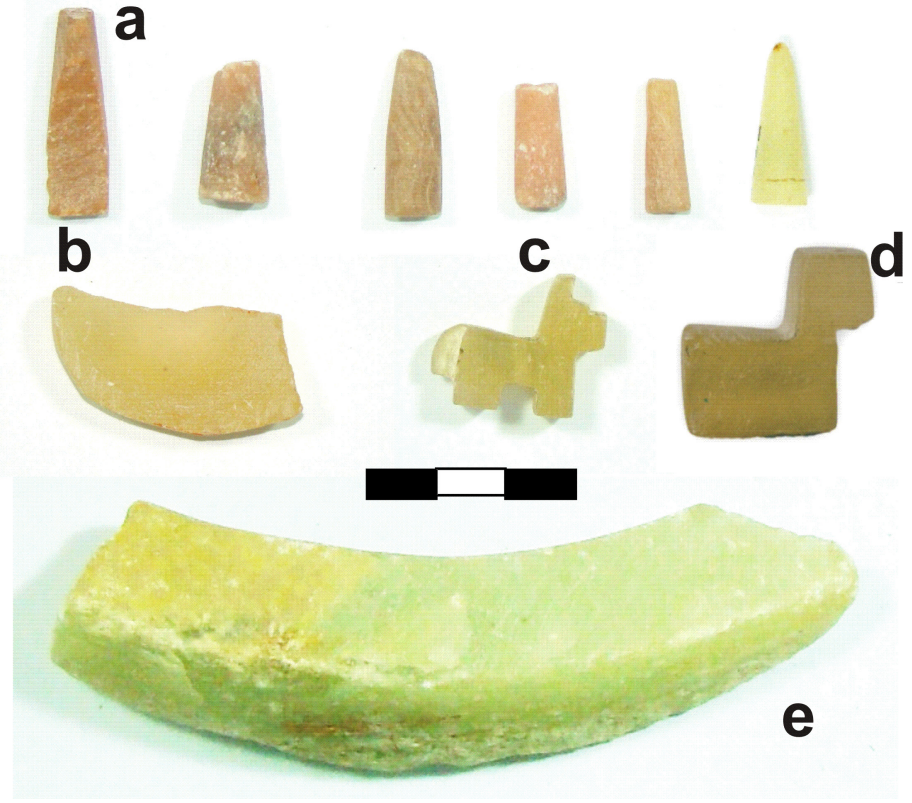

Figura 10. (a) Preformas de pendientes confeccionadas en travertinos y ónix (MLPAR-S $/ \mathrm{N}^{\circ}$, Colección Muñiz Barreto). (b) Fragmento de recipiente de ónix (MLP-AR$\mathrm{S} / \mathrm{N}^{\circ}$, Colección Muñiz Barreto). (c) Illa zoomorfa de ónix (MLP-AR-N $\left.{ }^{\circ} 7365\right)$. (d) Illa zoomorfa de ónix (Colección del Museo Dr. Eduardo Casanova, FFyL-UBA, N ${ }^{\circ}$ 2266). (e) Fragmento de recipiente de travertino (MLP-AR-S/N ${ }^{\circ}$, Colección Muñiz Barreto).

(a) Preforms of rings made of travertines and onyx (MLP-AR-S/N ${ }^{\circ}$, Muñiz Barreto Collection). (b) Fragment of onyx container (MLP-AR-S/N ${ }^{\circ}$, Muñiz Barreto Collection). (c) Onyx zoomorphic miniature (MLP-AR- $\left.N^{\circ} 7365\right)$. (d) Onyx zoomorphic miniature (Museo Arqueológico Dr. Eduardo Casanova, FFyL-UBA, $N^{\circ} 2266$ ). (e) Fragment of travertine container (MLP-AR-S/N ${ }^{\circ}$, Muñiz Barreto Collection).

posible que el tránsito de estas rutas transversales haya sido continuo, dada la cantidad de materias primas registradas en los talleres del pucará y, además, porque debieron ser aprovechadas para trasladar los objetos terminados hacia distintos enclaves del Imperio. Hacemos mención que en este trabajo no proponemos asignar una única función a los caminos, por ejemplo, ligada al caravaneo para el transporte de materias primas y bienes, ya que entre otras posibilidades debieron utilizarse para el desplazamiento de trabajadores hasta los campos agrícolas y complejos mineros, y para la circulación de las huestes militares.

Para el sector central de la quebrada, consideramos que parte de la red vial incaica extendida hacia el oriente, particularmente la vinculada a los sitios de carácter defensivo como El Durazno y Pueblito Calilegua (Nielsen 1989), en una primera etapa del proceso de anexión de la región debió funcionar principalmente para definir los límites fronterizos. Una vez lograda la ocupación efectiva, creemos que estos caminos sumaron otras funciones relacionadas al servicio de la religión y la producción agrícola. En este sector, el flujo de recursos posiblemente estuvo fuertemente ligado con la circulación de los excedentes generados en los campos de cultivo del Alfarcito y Ovejería. Este complejo productivo, con grandes extensiones de andenes con arquitectura incaica, tal como se mencionó, cuenta con cuatro segmentos de caminos prehispánicos reutilizados hasta el presente que permiten acceder a estos campos agrícolas en cuatro horas y descender desde ellos hasta el Pucará de Tilcara en tan solo dos horas. Las vías paralelas que identificamos en uno de ellos y que podrían definirse como caminos de doble mano (Hyslop 1984), separadas entre sí por solo $4 \mathrm{~m}$, quizás estén indicando su uso intensivo durante la época de cosecha para transportar hasta el pucará recursos agrícolas para ser distribuidos entre los artesanos especializados dedicados a la producción metalúrgica y lapidaria. Estos trayectos también conducen a los tambos de Casa Colorada y Rupaska, claves en la articulación del Pucará de Tilcara con los Valles Orientales. A manera de hipótesis proponemos que las puntas de proyectil de pedernal, que se habrían elaborado en los talleres del pucará, sirvieron para abastecer las guarniciones de la frontera oriental del Imperio, instaladas para 
frenar los avances de las distintas etnias que habitaban las tierras bajas del Gran Chaco.

Los caminos emplazados en la Serranía de Tilcara, al vincular de forma directa a las principales wakas con el Pucará de Tilcara, también debieron tener un rol destacado en el marco de diferentes festividades religiosas. El pucará cuenta con un importante edificio ceremonial que por sus características constructivas y el tipo de materiales encontrados en su interior debió ser uno de los principales escenarios locales para promulgar las bases religiosas incaicas (Otero y Ochoa 2011; Ochoa y Otero 2018). En esta articulación del Pucará y de otros poblados del sector central, como La Huerta, con las wakas, los tambos y los sitios estratégicos de control, la red vial además debió controlar de forma ampliada el flujo de personas que se desplazaban durante las peregrinaciones religiosas (Ochoa 2016; Ochoa y Otero 2017, 2018). A su vez, pudo funcionar como un canal para transportar diferentes ofrendas destinadas a la veneración de estas wakas. Una parte de la producción de los bienes artesanales confeccionados en el pucará debió entregarse como ofrendas en el marco de los ritos de fertilidad, principalmente las illas de alabastro. En el seno de distintas comunidades peruanas y bolivianas, por siglos el alabastro en su estado natural o trabajado se ha vinculado a Illapa, el rayo como deidad, siendo uno de los elementos más destacados en los rituales propiciatorios de fertilidad y de evocación de los ancestros para su intercesión ante eventos climáticos desfavorables (Manríquez 1999; Oro Rodríguez 2015).

Por otro lado, también como parte de esa geografía sagrada de los incas (Pease 1995:272), en las faldas de los cerros donde se emplazaron los santuarios de altura se registraron vertientes que dan origen a los ríos de la Huerta y el Huasamayo. Estos ríos, tributarios del Río Grande, son cursos de aguas permanentes que durante la época prehispánica con total seguridad abastecieron a los mencionados Pucará de Tilcara y La Huerta. Por su capacidad regeneradora, estas fuentes de agua también debieron considerarse wakas, a las que se debía ofrendar illas y bebidas para promover la abundancia de recursos (Ochoa y Otero 2018). Los tramos de camino inca más notables de la región se registraron próximos a estas vertientes y sobre los faldeos de estas wakas. Se trata de calzadas rituales empedradas, enlajadas, amojonadas y con escaleras de excelente calidad constructiva. Ejemplo de esto son el excepcional segmento de camino inca de $11 \mathrm{~m}$ de ancho emplazado entre muros de piedra y amojonado a partir de dos grandes tokankas, que conduce al santuario de altura de la serranía de las Ánimas (Ochoa 2019) (Figura 11a), los tramos empedrados que descienden desde el Abra Colorada al pueblo de Caspalá (Raffino 1981) para luego ascender al Cerro Chasquillas (Nielsen 1989), los trayectos también empedrados y amojonados trazados a más de $4.000 \mathrm{msm}$, aún en uso durante las peregrinaciones católicas al Abra de Punta Corral (Ochoa y Otero 2018) (Figura 11b) y el acceso mediante escaleras confeccionadas en cuarcita rosada utilizado para ascender al santuario de altura del Cerro Sixilera (Ochoa 2016, 2017b; Ochoa y Otero 2017) (Figura 11c).

Otro punto a considerar, en relación a las características de estos trayectos, es que también
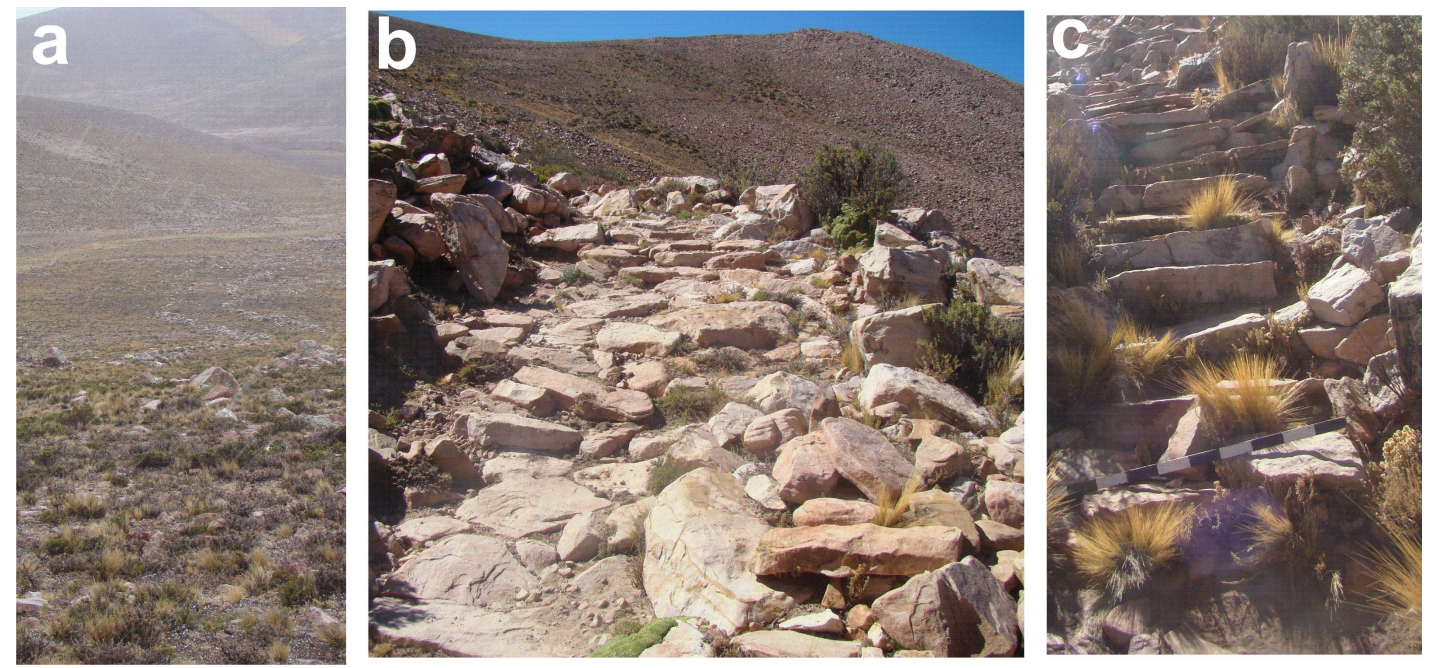

Figura 11. (a) Trayecto de camino inca de $11 \mathrm{~m}$ de ancho construido a partir de la técnica de entre muros de piedras y amojonado por dos grandes Tokankas utilizado para ascender al santuario de altura de la serranía de las Ánimas. (b) Segmento de camino empedrado y amojonado con grandes piedras en el acceso al santuario de altura del Abra de Punta Corral. (c) Peldaños incaicos del trayecto de qhapaq ñan que asciende al santuario de altura del cerro Sixilera.

(a) Inca road of $11 \mathrm{~m}$ wide section built using the building technique between stone walls and marked by two large Tokankas used to climb to the high-altitude sanctuary located on the summit of the mountainous area of Ánimas. (b) Segment of paved road marked with piles of stones in the access to the high-altitude sanctuary of Abra de Punta Corral. (c) Inca steps of the path of qhapaq nan that that climbs to the high-altitude sanctuary of Sixilera hill. 
conectan a las wakas entre sí. El Cerro Sixilera y la Serranía de las Ánimas, los dos picos más elevados del sector central de la quebrada, se encuentran en la misma longitud oeste $\left(65^{\circ} 15^{\prime} 57^{\prime}\right.$ '). En línea recta hacia el norte, el Hornocal, por sus características también debió considerarse un cerro tutelar $\left(65^{\circ}\right.$ 08 ' 18"). La disposición de estos cerros sobre la misma línea de los sectores más elevados de la Serranía de Tilcara y la red vial que los articula, a través del Abra del Remate, pudo ser aprovechada a modo de frontera político religiosa para demarcar el extremo oriental del territorio. A su vez, el Cerro Sixilera, ubicado en la línea del Trópico de Capricornio, debió contar con una doble connotación simbólica durante las celebraciones incaicas que buscaban organizar la producción agrícola en base a los ciclos estacionales y los calendarios rituales. Vale reiterar que dos de estos tres cerros aún son escenario de celebraciones religiosas en el marco de peregrinaciones católicas (Ochoa y Otero 2018).

La dimensión ritual del tránsito también se manifiesta en las ofrendas que se depositaban en distintos puntos de los caminos que dieron relieve a la traza simbólica del espacio. Tal es el caso de los materiales arqueológicos detectados en la apacheta del Abra de Tokante y en las Tokankas próximas al Tambo de Qaqaral. Desde ambos puntos se visualiza de forma directa a dos de las tres principales wakas que caracterizamos, el Cerro Sixilera y la Serranía de las Ánimas (Ochoa 2019).

Por último, otro aspecto a tener en cuenta sobre la lógica del tránsito y el manejo de la producción es que los caminos emplazados sobre las quebradas tributarias, a modo de diagonales vincularon de la manera más corta distintos "nodos" (sensu Berenguer et al. 2011). Se trata de ejes de interacción transversal de larga extensión, por ejemplo, Casabindo-Tilcara o Susques-Humahuaca (Figura 2), que llegaron a vincular los principales poblados de la Puna, algunos de ellos incluso definidos como cabeceras políticas (Albeck 2007), con los de la quebrada. Otra característica de estas rutas diagonales son las encrucijadas o cruces de caminos que detectamos en distintos puntos, que debieron servir para irradiar trayectos hacia distintas direcciones. A lo largo de la quebrada troncal también identificamos encrucijadas asociadas a los grandes centros administrativos, como en el Pucará de Tilcara, La Huerta de Huacalera y el Pucará de Peñas Blancas, asociadas tanto a las rutas transversales como a las diagonales recién mencionadas.

\section{Conclusión}

En base a las evidencias presentadas proponemos que la Quebrada de Humahuaca se constituyó como una frontera interna del Tawantinsuyu, organizada bajo una administración que debió reproducir diversas estrategias políticas de las áreas centrales del Imperio para lograr el control directo del sistema productivo. En este escenario, además, la quebrada posiblemente funcionó como un paso intermedio hacia la frontera extrema (Hyslop 1998) ubicada en el borde suroriental del Kollasuyu, en el límite entre la Serranía de Tilcara y los Valles Orientales. El sistema de rutas transversales que registramos en el sector central, y que llegan hasta el borde de la Cejas de Selva del Gran Chaco, demuestran esta construcción delimitada del espacio. De allí que consideremos al qhapaq ñan no solo como un elemento tangible del poder político, sino también como un rasgo de demarcación, integración y consolidación de identidades. No obstante, al igual que en otras regiones de los Andes cumplió con otros fines. En este caso sirvió para alcanzar los intereses extractivos y productivos del Estado. El sistema vial se materializa en el paisaje como una marca de poder desplegada en concordancia con el aparato productivo montado para la explotación de los recursos locales, siendo un elemento fundamental para el desarrollo de la agricultura de manera intensiva, el traslado y procesamiento de materias primas de otros ambientes y el flujo de trabajadores y bienes suntuarios. Por otro lado, el registro de la dimensión espacial y de las variadas técnicas constructivas para modelar todo tipo de geografías, llevó a que consideremos al qhapaq ñan como uno de los principales indicadores de innovación tecnológica e inversión estatal en el área. Actualmente es posible afirmar que existió una gran intervención para la reconfiguración del potencial productivo local mediante su control directo (Otero et al. 2018).

Además de ser una parte indispensable del sistema productivo incaico, los caminos fueron fundamentales para la reorganización de las prácticas religiosas y el sostenimiento de todo tipo de relaciones humanas. En este sentido, designar funciones particulares a cada tramo registrado o evaluar sus características constructivas de forma aislada, puede llevar a un análisis recortado de los mecanismos que utilizó el Estado para incorporar diferentes regiones a la geografía sagrada de su territorio. A modo de reflexión final, sostenemos que no todas las regiones definidas como periféricas o distantes al centro del Imperio fueron superficialmente reorganizadas para ser incluidas en la estructura política y económica del Estado. El avance en nuestras investigaciones conduce a pensar que este pudo ser el caso de la Quebrada de Humahuaca. Esta región habría sido estructurada de manera particular, a pesar de su proximidad al área de frontera. Entendemos que se trató de una 
provincia con características significativas, donde el Inca llegó a aplicar niveles de integración política cercanos a los utilizados en algunas regiones de los Andes Centrales.

Agradecimientos: En primer lugar, queremos agradecer al arquitecto Joaquín Trillo con quien prospectamos varios de los trayectos presentados en este artículo. Agradecemos también a los tres evaluadores del manuscrito, quienes con sus comentarios y sugerencias fortalecieron el artículo. A los encargados y técnicos de los Museos Arqueológico "Dr. E. Casanova" y Etnográfico "JB Ambrosetti", ambos de la Facultad de Filosofía y Letras (UBA), y del Museo de La Plata de la Facultad de Ciencias Naturales y Museo (UNLP). Por último, deseamos transmitir nuestro agradecimiento a los pobladores que viven "en el cerro adentro", en las comunidades de Laguna Colorada, el Portillo, Casa Grande, Vizcarra, La Huerta, Sixilera, Huichaira, y El Alfarcito, ya que en muchas ocasiones abrieron las puertas de sus hogares para alojarnos.

\section{Referencias Citadas}

Albeck, M.E. 1992. El ambiente como generador de hipótesis sobre la dinámica sociocultural prehispánica en la Quebrada de Humahuaca. Cuadernos de Investigación 3:95-106.

Albeck, M.E. 2016. Producción y lógica de la red vial incaica en el extremo septentrional del NOA. Arqueología 22 (1):61-79.

Albeck, M.E, MA. Zaburlín y K. Menacho 2007. Espacios productivos y simbólicos. La dominación inca en Casabindo. Actas del XVI Congreso Nacional de Arqueología Argentina. Tomo II pp. 549-554, Universidad Nacional de Jujuy. San Salvador de Jujuy.

Berenguer, J. y D. Salazar 2017. Territorialización del modelo minero inkaico en el río salado: Una aglomeración productiva entre Lipez y San Pedro de Atacama. Boletín del Museo Chileno de Arte Precolombino 22 (1):51-69.

Berenguer, J., C. Sanhueza e I. Cáceres 2011. Diagonales incaicas, interacción interregional y dominación en el altiplano de Tarapaca. En Ruta: Arqueología, Historia y Etnografía del Tráfico Sur Andino, editado por L Nuñez y A. Nielsen, pp. 247-283. Encuentro Grupo editor, Córdoba.

Chacaltana, S., E. Arkush y G. Marcone (eds.) 2017. Nuevas Tendencias en el Estudio de los Caminos. Ministerio de Cultura del Perú, Lima.

Fernández, J. 1998. Arqueología de la Cueva del Portillo, Departamento de Humahuaca, provincia de Jujuy. Avances en Arqueología 3:41-70.

González, A. 1982. Las provincias inca del antiguo Tucumán. Revista del Museo Nacional 46:317-380.

González Godoy, C. 2017. Arqueología vial del Qhapaq Nan en Sudamérica: Análisis teórico, conceptos y definiciones. Boletín del Museo Chileno de Arte Precolombino 22 (1):15-34.

González Turu, E. y C. Vitry 2006. Nevado de Chañi. Edición de los autores, Salta.

Hyslop, J. 1984. The Inka Road System. Academic Press, Orlando.

Hyslop, J. 1998. Las fronteras estatales extremas del Tawantinsuyu. En La Frontera del Estado Inka, editado por T. Dillehay y P. Netherly, pp. 33-51. BAR Internacional series 442, Oxford.

Mánriquez, V. 1999. El término Ylla y su potencial simbólico en el Tawantinsuyu. Una reflexión acerca de la presencia inca en Caspana (río Loa, desierto de Atacama). Estudios Atacameños 18:107-118

Moralejo, R. 2017. Arqueología y paisaje en el interfluvio de Zapata, Catamarca, noroeste de Argentina. Boletín del Museo Chileno de Arte Precolombino 22 (1):119-136.
Nielsen, A. 1989. La Ocupación Indígena del Territorio Humahuaca Oriental durante los Periodos de Desarrollos Regionales e Inka. Tesis Doctoral. Universidad Nacional de Córdoba, Córdoba.

Ochoa, P.A. 2016. Configuración del Paisaje Prehispánico del Sector Central de la Quebrada de Humahuaca (Jujuy, Argentina). Arqueoantropológicas 6 (6):25-46.

Ochoa, P.A. 2017a. Arquitectura para la materialización del poder. Aportes a partir del estudio de nuevos sitios identificados en la quebrada de Sixilera (Quebrada de Humahuaca, Argentina). Mundo de Antes 11:171-194.

Ochoa, P.A. 2017b. Huacas y Vírgenes: reordenamiento territorial en el sector central de la Quebrada de Humahuaca (Jujuy, Argentina). Revista Española de Antropología Americana 47:91-109.

Ochoa, P.A. 2019. Los paisajes rituales del sector central de la Quebrada de Humahuaca (Jujuy, Argentina). Nuevos aportes a partir del estudio del Qhapaq Nan. Cuadernos del Instituto Nacional de Antropología y Pensamiento Latinoamericano. Series especiales 7 (1):33-47.

Ochoa, P. A. y C. Otero 2017. Contribuciones al estudio de la vialidad incaica en el sector central de la Quebrada de Humahuaca (Jujuy, Argentina). Boletín del Museo Chileno de Arte Precolombino 2 (2):83-101.

Ochoa, P.A. y C. Otero 2018. Wak'as en luna llena. Aportes para el estudio de la ritualidad andina en el sector central de la Quebrada de Humahuaca (Jujuy, Argentina). En Concepciones sobre el Clima en el Mundo Andino. Reflexiones y Debate Interdisciplinar, editado por R. Bustamante Zenteno y N. Antequera Duran, pp. 39-58. Universidad Mayor de San Simón, Cochabamba.

Oro Rodríguez, V. 2015. Retablos y Piedras Santos. La Materialidad de las W'akas. MUSEF, La Paz.

Otero, C. 2015. Distribución y consumo de cerámica inca en el Pucará de Tilcara (Quebrada de Humahuaca, Argentina). Chungara Revista de Antropología Chilena 47 (3):401-414.

Otero, C., M.B. Cremonte y P.A. Ochoa 2018. La construcción del poder incaico en la Quebrada de Humahuaca (Jujuy, Argentina). En Interpretando Huellas: Arqueología, Etnohistoria y Etnografía de los Andes y sus Tierras Bajas, editado por M.A. Muñoz, pp. 227245. Grupo Editorial Kipus. Universidad Mayor de San Simón, Cochabamba.

Otero, C. y P.A. Ochoa 2011. Primeras aproximaciones a la materialización del tiempo y las prácticas productivas especializadas en Tilcara (Quebrada de Humahuaca, Jujuy). Estudios Sociales del NOA, Nueva Serie 11:101-124. 
Otero, C. y M. Tarragó 2017. Reconstructing Inca socioeconomic organization through biography analyses of residential houses and workshops of Pucara de Tilcara (Quebrada de Humahuaca, Argentine). Journal of Anthropology and Archaeology 5 (1):55-72.

Pease, F. 1995. Las Crónicas y los Andes. Pontificia Universidad Católica del Perú, Lima.

Pimentel, G. 2009. Las huacas del tráfico. Arquitectura ceremonial en rutas prehispánicas del Desierto de Atacama. Boletín del Museo Chileno de Arte Precolombino 14 (2):9-38.

Raffino, R. 1981. Los Inkas del Kollasuyu. Ramos Americana, Buenos Aires

Rowe, J.H. 1946. Inca culture at the Time of the spanish conquest. En Handbook of South American Indians Vol. 5, editado por J. Steward, pp. 183-330. Smithsonian Institution, Washington DC.

Salas, A. 1945. El Antigal de Ciénaga Grande (Quebrada de Purmamarca, Pcia. De Jujuy). Publicación del Museo Etnográfico. Facultad de Filosofía y Letras, Universidad de Buenos Aires.

Sánchez, S. 2004. Discursos y alteridades en la Quebrada de Humahuaca (Provincia de Jujuy, Argentina). Identidad, parentesco, territorio y memoria. Boletín de Arqueología PUCP 8:111-132.
Tarragó, M. 2013. Reflexiones sobre la arqueología del Noroeste Argentino en el ámbito de los Andes Circumpuneños. En Las Tierras Altas del Área Centro Sur Andina entre el 1000 y el 1600 d.C., editado por M.E. Albeck y M.B. Cremonte, pp. 23-42. Ediunju, San Salvador de Jujuy.

Uribe Rodríguez, M. 1999. La arqueología del Inka en Chile. Revista Chilena de Antropología 15:63-98.

Valcárcel, L. 1934. Sajsawaman redescubierto. Revista del Museo Nacional 3 (1-2):3-36.

Valcárcel, L. 1935. Los trabajos arqueológicos en el Dpto. del Cusco. Sajsawaman redescubierto (III). Revista del Museo Nacional 4 (1):1-24.

Vitry, C. 2017. El rol del Qhapaq Nan y los Apus en la expansión del Tawantinsuyu. Boletín del Museo Chileno de Arte Precolombino 22 (1):33-47.

Williams, V. 2004. Poder estatal y cultura material en el Kollasuyu. Boletín de Arqueología PUCP 8:209-245.

Williams, V. y P. Villegas 2017. Rutas y senderos prehispánicos como paisajes. Las quebradas altas del valle Calchaquí medio (Salta). Boletín del Museo Chileno de Arte Precolombino 22 (1):71-94.

\section{Notas}

${ }^{1}$ El término wamani refiere a la organización de un territorio en provincia inca. Estas wamani tuvieron centros políticos de destacada jerarquía, que funcionaron como capitales. En el Noroeste argentino, el Pucará de Tilcara pudo ser la capital de la provincia de Humahuaca, La Paya de la provincia de Chicoana, Tolombón de Tucumán y el Shincal de Quire Quire (González 1982; Williams 2004).

${ }^{2}$ La Quebrada de Humahuaca se destaca por su potencial agrícola. Se estima que en la región más de 2.000 ha de campos de cultivo prehispánicos conformaron los complejos agrícolas de El Alfarcito, Ovejería, Sixilera, El Churcal, El Moya, Capla y Coctaca-Rodeo. Estos campos agrícolas, emplazados de forma interconectada sobre la serranía de Tilcara, fueron ocupados desde el período Formativo hasta el período Inca.

${ }^{3}$ Entre estas última mencionamos apachetas, tokankas, punkus, oquedades, acumulaciones de piedra, cajas, sepulcros y muros.

${ }^{4}$ Rectitud, preparación de la superficie, pendiente y otros rasgos viales, tales como punto de conexión con otros caminos y asentamientos laterales.

5 Ancho de la arteria, detalles constructivos (rampas, muros de contención, escalinatas, sistemas de drenaje, banquinas) y apilamientos de piedra de origen antrópico. 